\title{
NUMERICAL ANALYSIS ON HOT WATER STORAGE TANK INTEGRATED WITH PHASE CHANGE MATERIALS
}

\author{
ELISANGELA JESUS D’OLIVEIRA, SOL CAROLINA COSTA PEREIRA \& ULUGBEK AZIMOV \\ Department of Mechanical and Construction Engineering, Northumbria University at Newcastle, UK
}

\begin{abstract}
The combination of solar collectors with latent heat thermal energy storage system (LHTESS) has been employed to utilise solar energy more effectively, as this technology can provide a balancing function to match the variability in supply and demand, reducing the supply challenges for electricity. Computational fluid dynamic (CFD) has been proven to be an important mathematical tool for optimisation purposes; thus, it can be used to validate different design configurations. This study aims to conduct a numerical simulation using ANSYS/Fluent to investigate the thermal behaviour of a phase change material (PCM) storage system integrated with a thermal solar collector and compare it with experimental data from the literature review, with the objective of investigating the appropriate selection of the storage media material. The good correspondence between the numerical simulation results and the experimental results validates the numerical model proposed to be used with confidence to evaluate the performance of the solar collector in different configurations. The configurations evaluated include different types of phase change materials and NEPCM (paraffin wax, RT64HC, beeswax, RT64HC with 1 wt. $\%$ of $\mathrm{Cu}$, beeswax with 0.15 wt.\% of GNPs). A time step sensitivity analysis was conducted and the results obtained showed that the numerical model is not time dependent. From the results obtained beeswax with $0.15 \mathrm{wt} . \%$ had the highest peak of the average temperature of the water, however the integration of PCMs does not offer major benefits in terms of heat gains to compensate the highest cost related to these materials.
\end{abstract}

Keywords: solar water heaters, thermal energy storage, phase change material (PCM), latent heat storage, computational fluid dynamics (CFD), thermal performance.

\section{INTRODUCTION}

Renewable energy sources are known to have an enormous potential for the supply of clean and secure energy. Hence, more efficient and cost-effective methods of harvesting solar energy are the primarily focus on many studies. Domestic water heating systems are an excellent application for utilising the solar energy, however the wide distribution of these systems are reliant on the accessibility of reliable storage methods [1]. Many studies showed that the implementation of phase change materials (PCMs) in solar domestic water heating systems (SDWHS) could significantly increase the overall efficiency and reliability of the system [2]-[9], due to its large energy storage capacity and isothermal behaviour during charging and discharging processes [10], [11].

A numerical study consisting of a solar collector storage integrated with two different PCMs (myristic acid and RT42-graphite) was proposed. According to the results, the Latent heat thermal energy storage (LHTESS) is more effective for both PCMs comparing with the sensible heat system as it allows lower thermal losses and better heat preservation [12]. Different case scenarios of a system consisting of series of identical tubes embedded with three different PCMs (n-octadecane, paraffin and stearic acid) were investigated. From the results, the incorporation of PCM into the system is not as beneficial, as there is not a great eat preservation [13]. Several numerical studies were conducted to investigate the effect of three different melting processes of high temperature PCM including pure conduction, conduction and natural convection. According to the results, including the turbulence flow led to a higher mixing effect which resulted in a more uniform process with a lower peak 
temperature and higher heat transfer rate [14]. Studies do not often consider the application of metallic PCMs due to the high weight and cost related to these materials. However, this study has numerically and experimentally investigated the charging and discharging of metallic PCMs and compared with solar salt PCMs. From the results, the metallic PCMs showed a higher performance and the melting process of these materials are dominated by the thermal conduction [15]. Numerical simulations were performed to analyse the impact of integrating Nanoparticle-enhanced phase change materials (NEPCMs) in a hot water tank to shift the peak load. According with the simulations results, NEPCMs can shift the power demand for a longer period compared to pure PCMs [16].

Many studies have been conducted on the effects of encapsulating the PCMs, to increase its thermal conductivity [17]. The PCM encapsulation techniques are classified accordingly with size and shape of the capsules, which can be cylindrical and made [18]. The storage materials are going to be encapsulated in a cylindrical container made of aluminium to increase the thermal conductivity. The cylindrical shape encapsulation has numerous advantages due to it being easy to manufacture and install into the thermal energy storage tank [19].

Reviewed the opportunities around the technical and economic aspects of PCMs for the application in SDWHS. The authors discussed that in terms of technical aspects, there is still loads of work to be done in improving the characteristics of PCM in SDWHS application. As it is shown in previous studies, there are still discrepancies on the results conducted by different researchers on the benefits of incorporating PCMs into SDWHS [20]. Hence, this study reports the outcome of the numerical simulations through ANSYS Fluent on the application of encapsulated PCMs in a water-PCM storage system, which has been validated against experimental results conducted by Shareef et al. [21]. The model assumes a forced circulation, to obtain a well-defined mass-flow rate through the entire system. The selection of the appropriate storage material is investigated by conducting different case scenarios, including PCMs with different melting temperatures, latent heat capacity as well as the inclusion of high conductive nanoparticles. The comparison is also made against the numerical model without the PCM to evaluate the overall thermal performance of the system.

\section{NUMERICAL MODEL}

\subsection{Physical model and computational domain}

In this study, two different models were developed, the first one is the geometry of a cylindrical steel water storage tank with a capacity of 49 litres, with dimensions of $750 \mathrm{~mm}$ high and $285 \mathrm{~mm}$ inner diameter (see Fig. 1(a)). The diameter of the inlet and outlet pipes is $40 \mathrm{~mm}$, and the length is $300 \mathrm{~mm}$. The second model has the exact same dimensions of the water storage tank; however, in this model, 32 cylindrical aluminium containers filled with a PCM were integrated into the tank. The PCM containers were located into two rows of 16 containers each, and the volume of each container is 0.3 litres. It is important to note that although the majority of the dimensions were obtained from the study conducted by Shareef et al. [21], some of the dimensions were not included; thus, the geometries are not exactly the same.

As both models are symmetric, a symmetry plane was set as a boundary condition to reduce the complexity of the model and consequently the overall computational cost. Fig. 1(b) and 1(c) show the mesh profile of both models, which both had a hybrid element of hexahedrons and tetrahedrons. For the first model, the water tank, the number of elements in 


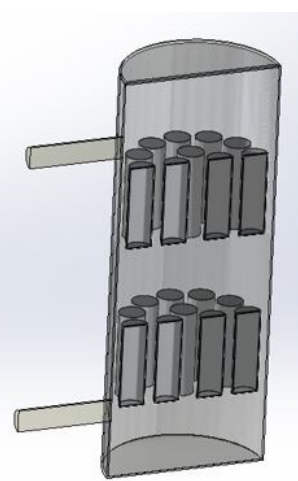

(a)

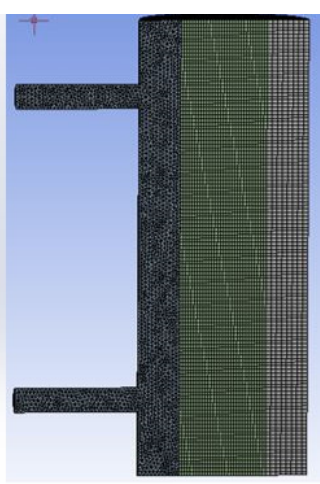

(b)

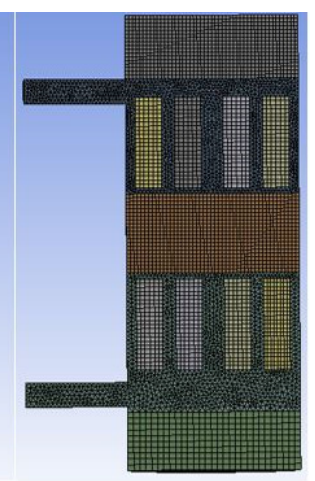

(c)

Figure 1: (a) Tank geometry; (b) Water tank mesh profile; and (c) Water tank with cylindrical containers mesh profile.

the mesh is 234,618 . For the second model, the water tank with the cylindrical containers, the number of elements in the mesh is 421,044 . Table 1 shows the thermophysical properties of the PCMs and NEPCMs based on the literature and data provided by the manufacturer.

Table 1: Thermophysical properties of the PCMs and NEPCMs.

\begin{tabular}{|l|c|c|c|c|c|}
\hline Property & Water & $\begin{array}{c}\text { Paraffin } \\
{[21]}\end{array}$ & $\begin{array}{c}\text { RT64HC } \\
{[22]}\end{array}$ & $\begin{array}{c}\text { RT64HC + 1 } \\
\text { wt.\% Cu [22] }\end{array}$ & $\begin{array}{c}\text { Beeswax + } \\
0.15 \text { wt.\% } \\
\text { GNPs [23] }\end{array}$ \\
\hline Melting point $\left({ }^{\circ} \mathrm{C}\right)$ & 0 & $44 \pm$ & 64 & 64 & 62.59 \\
\hline $\begin{array}{l}\text { Latent heat of } \\
\text { fusion }(\mathrm{kJ} / \mathrm{kg})\end{array}$ & - & 190 & 250 & 184.37 & 163.23 \\
\hline $\begin{array}{l}\text { Density, solid, } \\
\left(\mathrm{kg} / \mathrm{m}^{3}\right)\end{array}$ & - & $930 \mathrm{~kg} / \mathrm{m}^{3}$ & $880 \mathrm{~kg} / \mathrm{m}^{3}$ & - & 789.47 \\
\hline $\begin{array}{l}\text { Density, liquid } \\
\text { phase (kg/m })\end{array}$ & 998.2 & $830 \mathrm{~kg} / \mathrm{m}^{3}$ & $780 \mathrm{~kg} / \mathrm{m}^{3}$ & 808.2 & 819.75 \\
\hline $\begin{array}{l}\text { Specific heat } \\
(\mathrm{J} / \mathrm{kg} . \mathrm{k})\end{array}$ & 4182 & 2100 & 2000 & 1944 & 534 \\
\hline $\begin{array}{l}\text { Thermal } \\
\text { conductivity } \\
\text { (W/m.K) }\end{array}$ & 0.6 & 0.21 & 0.2 & 0.2056 & 1.7 \\
\hline Viscosity (kg/m.s) & 0.001003 & 0.031 & 0.00585 & 0.00599 & 0.000175 \\
\hline $\begin{array}{l}\text { Thermal expansion } \\
(1 / \mathrm{K})\end{array}$ & - & 0.00011 & 0.00011 & 0.00011 & 0.00017 \\
\hline
\end{tabular}

\subsection{Governing equations}

The commercial software ANSYS-Fluent $2020 \mathrm{R}$ was used for modelling solidification and melting processes in the 3-D geometry of the representative computational region of the LHTESS (see Fig. 1(a)). The unsteady heat transfer, phase change process and fluid flow coupled with forced convection inside the hot water storage tank is governed by the 
continuity, momentum and energy conservation equation [24]. The enthalpy-porosity technique [25] was used to model the PCM melting and solidification. In this technique, the mushy zones of PCM are considered as porous media and the porosity of each element in the mushy zone is assumed to be equal to the liquid fraction of that element. The enthalpy of the material is computed as the sum of the sensible enthalpy, $h$, and the latent heat, $\Delta H$ [25]:

$$
H=h+\Delta H,
$$

where

$$
h=h_{r e f}+\int_{T_{r e f}}^{T} c_{p} d T,
$$

and $h_{r e f}$ is the reference enthalpy; $T_{r e f}$ is the reference temperature and $c_{p}$ is the specific heat at constant pressure.

The liquid fraction, $\beta$, can be defined as:

$$
\begin{array}{rrc}
\beta=0 & \text { if } & \mathrm{T}<\mathrm{T}_{\text {solidus' }} \\
\beta=1 \quad \text { if } & \mathrm{T}>\mathrm{T}_{\text {liquidus' }} \\
\beta=\frac{T-T_{\text {solidus }}}{T_{\text {liquidus }}-T_{\text {solidus }}} & \text { if } & \mathrm{T}_{\text {solidus }}<\mathrm{T}<\mathrm{T}_{\text {liquidus }}
\end{array}
$$

The latent heat content can be presented in terms of the latent heat of the material, L:

$$
\Delta H=\beta L \text {. }
$$

The latent heat content can vary between zero (for a solid) and 1 (for a liquid).

For solidification/melting problems, the energy equation is written as

$$
\frac{\partial}{\partial t}(\rho H)+\nabla \cdot(\rho v H)=+\nabla \cdot(k \nabla T)+S,
$$

where $\mathrm{H}$ is the enthalpy (defined in eqn (1)); $\rho$ is the density; $v$ is the fluid velocity and $S$ is the source term.

\subsection{Initial and boundary conditions}

Fig. 2 shows the 2D geometry of the computational model. The initial conditions of both water and the temperature of the PCM were assumed to be $24^{\circ} \mathrm{C}$. Thermal losses were considered in the model as convection losses in the external walls, the ambient temperature was set to $20^{\circ} \mathrm{C}$ [21], and the heat transfer coefficient of the wall was set as $7.5 \mathrm{~W} / \mathrm{m}^{2} \mathrm{~K}$. The volume flow rate during the charging period was set to $1 \mathrm{~L} / \mathrm{min}$. The inlet temperature was calculated based on the useful heat $(\mathrm{Qu})$ provided in the referenced experimental study [21]. The useful heat, $\mathrm{Qu}$, is input follows eqn (5) using a named expression in Fluent. Another expression was created to obtain the outlet temperature coming out of the pipe to calculate the initial temperature. The inlet temperature was then calculated by transforming the following equation:

$$
Q_{u}=\dot{m} \cdot c_{p} \cdot \Delta T
$$

where $m$ is the mass flow rate of water $(\mathrm{kg} / \mathrm{s}), c_{p}$ is the specific heat of water $(\mathrm{J} / \mathrm{kg} \mathrm{K})$ and $\Delta T$ is the temperature difference between inlet and outlet in the water $\left({ }^{\circ} \mathrm{C}\right)$. 


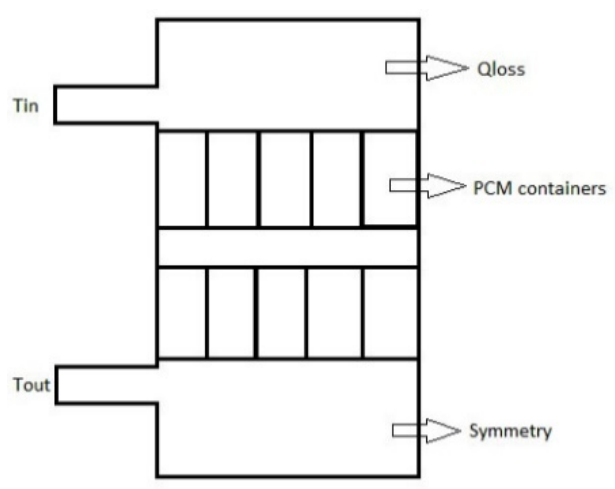

Figure 2: The 2D geometry of the computational model.

\subsection{Numerical set-up}

The Fluent's power law differentiating scheme and SIMPLEC method for pressure-velocity coupling was used to solve the momentum and energy conservation equations. The SIMPLEC scheme is adopted for the pressure correction equation. The time step was set to $5 \mathrm{~s}$; time independence test was investigated with time steps of $2 \mathrm{~s}$ and $10 \mathrm{~s}$. The convergency criteria for each time step are the residuals or the maximum number of iterations (20). The residuals were step $10^{-8}$ for the energy equation and $10^{-5}$ for all the other equations. The assumptions made in the proposed model are as follows:

- The working fluid is incompressible and the flow is laminar since the Reynolds number corresponding to this study is 591 in the water inlet pipe.

- Thermal properties of the PCM are constant in both the solid and the liquid phases.

- Natural convection effects in PCM are included through Boussinesq approximation.

\section{RESULTS AND DISCUSSION}

\subsection{Hot water storage tank with and without PCM (model validation)}

CFD numerical simulations of the two models of the hot water storage tank with and without the PCM containers filled with paraffin wax (melting temperature $44^{\circ} \mathrm{C}$ ) were conducted to analyse and compare the heat transfer performance of the tank. To validate the numerical model developed the results were compared against the experimental data obtained from the research studied conducted by Shareef et al. [21]; the validation of the model will allow the CFD model to be further investigated. Fig. 3(a) and 3(b) show the average water temperature inside the water storage tanks obtained from both the numerical and experimental results.

Fig. 3(a) provides with the average water temperature profile inside the hot water storage tank obtained from the numerical and experimental results [21] during a period of time. From 9:00 until 15:00 the water temperature increased due to the gains of heat from the increase in solar radiation; at that point in time the peak temperatures reached 73.1 and $69.7^{\circ} \mathrm{C}$, from the numerical and experimental results, respectively. From 15:00 until midnight the average water temperature starts to decrease as there is no more useful heat being gained due to the decrease of the solar radiation. During the discharging process, there is an evident 


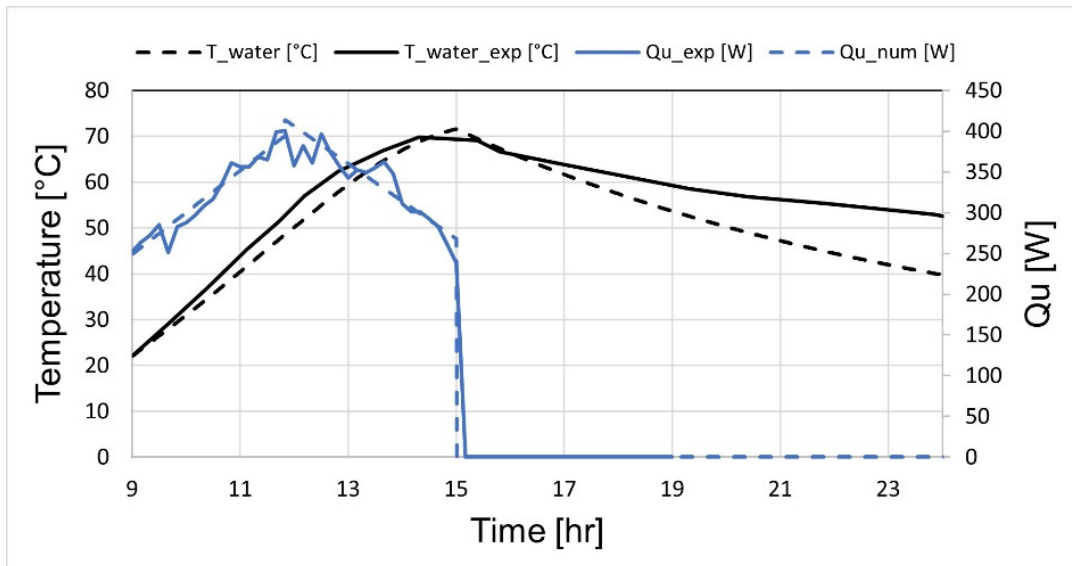

(a)

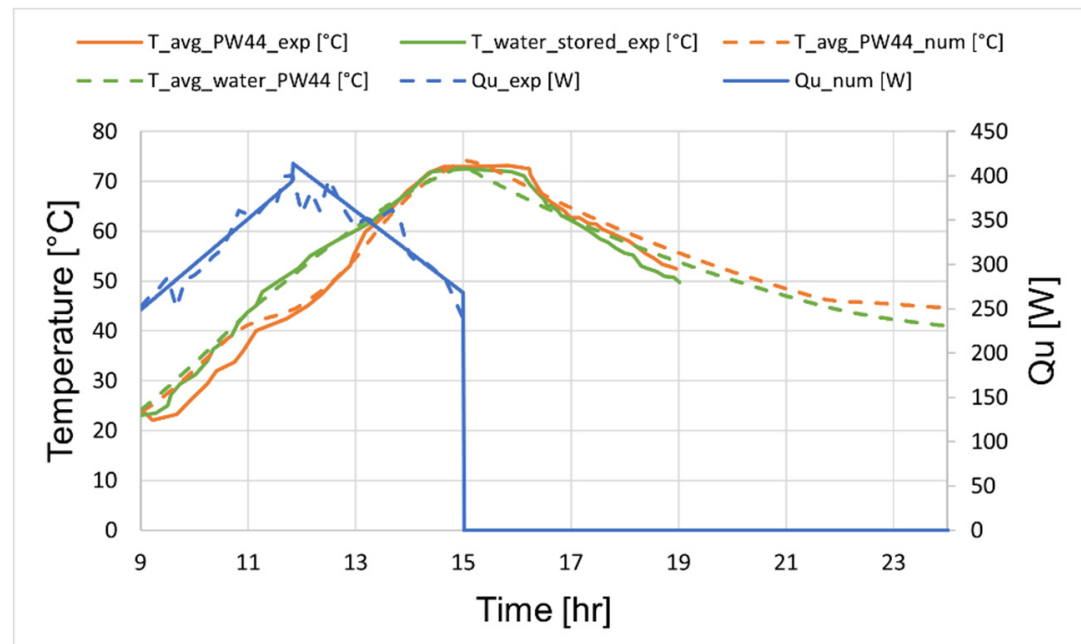

(b)

Figure 3: (a) Comparison between the experimental [21] and numerical results obtained from the water model; and (b) Comparison between the experimental and numerical results obtained of the average water temperature with the paraffin wax.

discrepancy between the numerical and experiment results, as the numerical model has higher thermal losses. This error might be attributed to wall insulation boundary of the cylindrical tank and other differences on the model geometry. The mean average errors from the experimental results are $9 \%$.

Fig. 3(b) shows the average water temperature profile inside the hot water storage tank with 32 PCM containers filled with paraffin wax obtained from the numerical and experimental results [21] during a period of time. From 9:00 until 15:00 the inlet temperature is increased due to solar radiation increase and consequently the PCM and water temperature rise; however, at that point the PCM temperature does not rise as fast as the water 
temperature. Around 11:00 the phase change of the paraffin starts to occur at temperatures around 44 to $46^{\circ} \mathrm{C}$. After 13:00, when the melting process is completed, both water and PCM temperatures rise at the same rate reaching the peak average water temperature of 73.1 and $72.4^{\circ} \mathrm{C}$, for the numerical and experimental analysis, respectively at 15:00. Afterwards, the temperature of the water and the PCM start to decrease at the same rate. The mean average errors from the experimental results are $2 \%$. The results obtained show a good agreement between the numerical and experimental results, thus, the numerical model can be used to further investigate the performance of tank.

Fig. 4 presents the temperature profile of the water and PCM inside the hot water storage tank at different times during the charging and discharging processes. At 9:30 the water starts to rise and the average temperature is around $26-32^{\circ} \mathrm{C}$; at that stage the heat transfer is mainly dominated by conduction. At 12:50 the average temperature of the tank is around 44 to $62^{\circ} \mathrm{C}$, and at that time the PCM inside the top containers are completed liquefied; however, there at the bottom PCM containers the simulation records a slow melting of the paraffin. This is given by the fact that natural convection heat transfer is more evident at the top part of the tank. At 17:00 the average temperature of the water is around $56-68^{\circ} \mathrm{C}$, at that stage the PCM at the top and bottom containers have completely melted. At 19:00 the discharging process has started, the inlet temperature starts to decrease to around $50^{\circ} \mathrm{C}$, and both the water and PCM temperature have started to decrease.

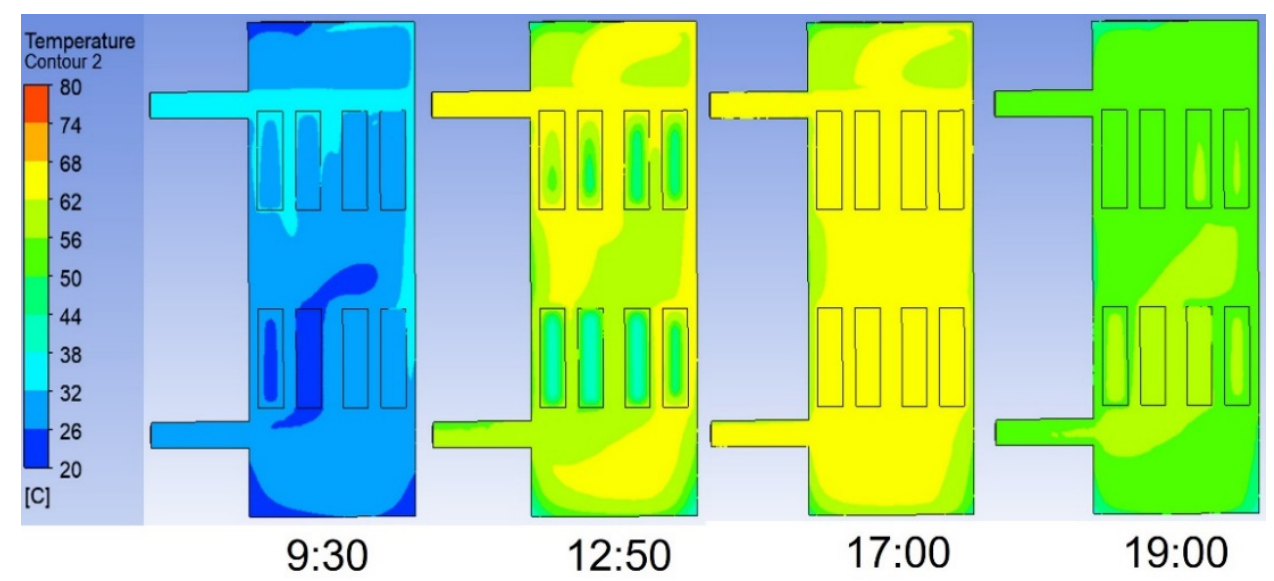

Figure 4: Evolution of the water and PCM temperature inside the hot water storage tank at the symmetry plane.

\subsection{Time dependence test (liquid fraction variation)}

As the problem being solved is unsteady, the independence of the solution from the time step is important to be examined; thus, a sensitivity analysis was conducted to assess the influence of three time steps, $2 \mathrm{~s}, 5 \mathrm{~s}$ and $10 \mathrm{~s}$ on the results obtained from the numerical model. For this matter, the liquid fraction of the paraffin wax under the three time steps was recorded. The liquid mass fraction is an indicator of the charging and discharging behaviour of the PCM; where 0 means the paraffin is solid and 1 that the paraffin is liquid.

To have a better understanding of the system response, Fig. 5 shows the variation of liquid fraction of the paraffin wax with a melting temperature of $44^{\circ} \mathrm{C}$ under different time steps, 


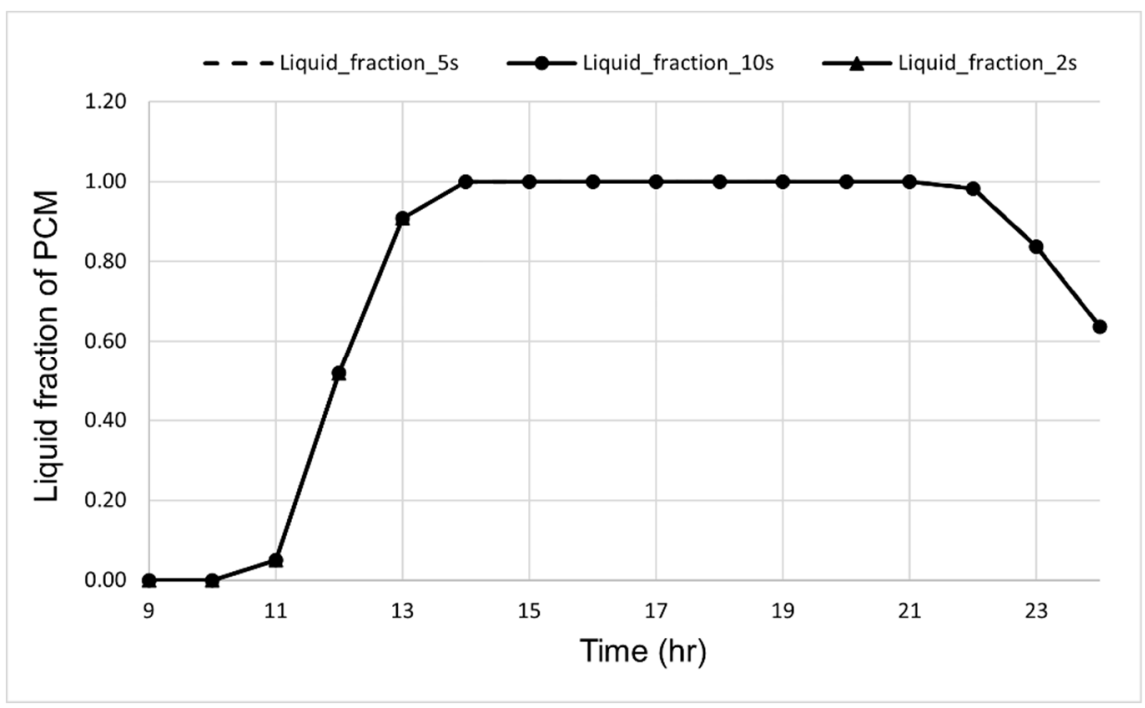

Figure 5: Variation of liquid fraction of the paraffin wax with a melting temperature of $44^{\circ} \mathrm{C}$ under different time steps.

from 9:00 until midnight. As the results obtained from the three different simulations are identical, the time independency of the model can be concluded.

\subsection{Comparison between different storage materials}

The selection of the storage media is a critical stage when developing LHTES, as the inappropriate selection of the PCM may not bring any benefits to the system. Having obtained a good agreement between the numerical and experimental results, the numerical model developed was used to analyse different storage materials with the same surrounding conditions to investigate the effects of different thermal properties such as melting temperature, latent heat and thermal conductivity. When selecting the PCM and NECPM the output of the solar collector was considerate in order to select a storage material with a melting temperature around the same output. Thus, the range of the melting temperature of the storage materials are between 44 and $64^{\circ} \mathrm{C}$. Table 1 shows all the thermal properties for the PCM and nano-enhanced PCMs.

Fig. 6 illustrates the numerical results obtained from the average water temperature inside the tank with the different materials, allowing a comparison between the cases to be done. From 9:00 to 11:00 during the charging process, the four case scenarios with the PCM containers have the same average water temperature variation; however, when the water temperature reaches $44^{\circ} \mathrm{C}$ at around 11:30 in the case with the paraffin wax (PW44) the water temperature stops rising as fast as the other three cases, as at that moment the PW44 is going through its melting process, thus, absorbing more energy of the water. After, 13:00 the beeswax with $0.15 \mathrm{wt} . \%$ of graphene nanoplatelets continues to rise faster than the rest of the cases reaching a peak of $77.14^{\circ} \mathrm{C}$ at $15: 00$, this rapid rise is due to the high thermal conductivity of the NEPCM. When comparing the case scenario of the tank PCM containers filled with beeswax with 0.15 wt.\% graphene nanoplatelets against the case with PW44 and without PCM, the case with beeswax reached a higher peak temperature of 4 and $7.14^{\circ} \mathrm{C}$, 
respectively. Although, the high thermal conductivity of the nano-enhanced beeswax has improved its charging process, during the discharging process the composite is also discharging at a faster rate. When comparing all the different case scenarios with the water model case, there are not major benefits gained with the inclusion of the PCM containers into the hot water storage tank.

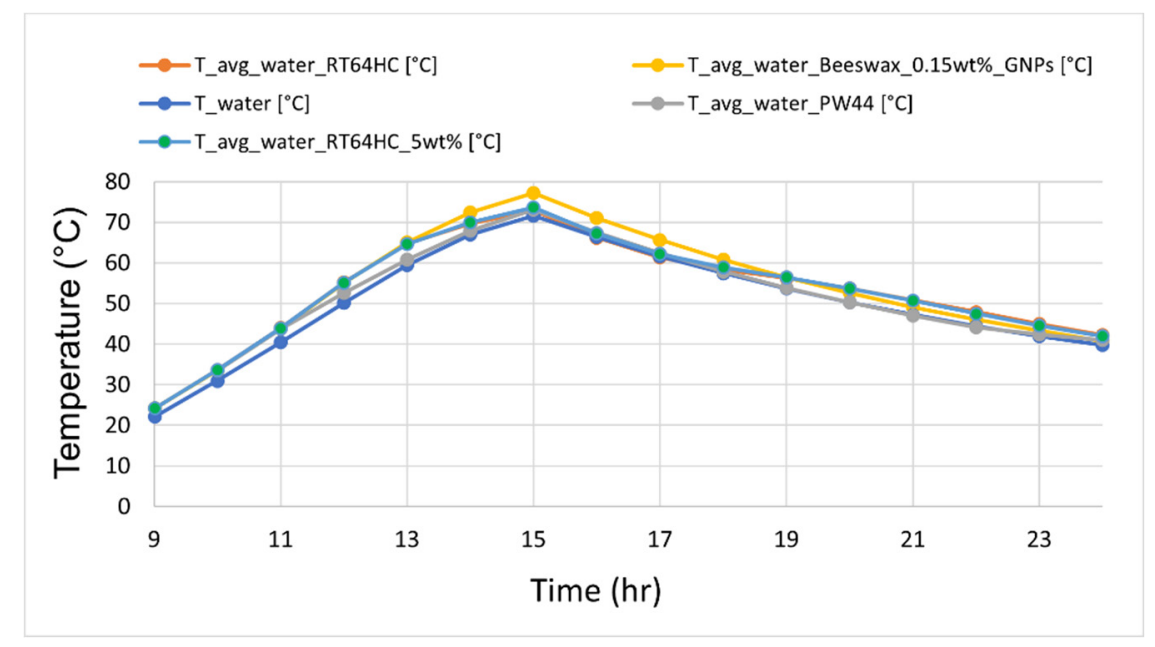

Figure 6: Average water temperature inside the tank between the different simulations.

\section{CONCLUSIONS}

In this paper, the aim was to assess the thermal performance of a hot water storage tank with different PCMs and NEPCMs using ANSYS Fluent to investigate further the effects of thermal properties such as melting temperature, latent heat capacity and thermal conductivity. Based on the results obtained, the following conclusions are presented:

- The selection of the appropriate PCM is extremely important when developing a LHTES.

- CFD results showed that at early stages the heat transfer is dominated by conduction and afterwards natural convection is more notable.

- The beeswax with the 0.15 wt.\% graphene had the highest peak of the average temperature of the water; however, the paraffin wax with a melting temperature of $44^{\circ} \mathrm{C}$ remained slightly hotter for longer compared to the other three materials. However, even though there were some slight improvements from the system without the PCM, the integration of PCMs into hot water storage tank does not offer some major benefits in terms of energy provided. Especially when considering the high cost related to these systems.

- Sensitivity analysis on the different time steps show that the results obtained from the numerical model are not time dependent.

As future work, the effects of the configuration and location of the PCM containers should be further analysed to maximise the benefits of integrating storage materials into domestic water heating systems. 


\section{ACKNOWLEDGEMENT}

This work was supported by EPSRC Centre for Doctoral Training in Renewable Energy Northeast Universities (ReNU), Project Reference EP/S023836/1.

\section{REFERENCES}

[1] Al-Hinti, I., Al-Ghandoor, A., Maaly, A., Naqeera, I.A., Al-Khateeb, Z. \& Al-Sheikh, O., Experimental investigation on the use of water-phase change material storage in conventional solar water heating systems. Energy Conversion and Management, 51(8), pp. 1735-1740, 2010.

[2] Sharma, A. \& Chen, C., Solar water heating system with phase change materials. International Review of Chemical Engineering, 1(4), pp. 297-307, 2009.

[3] Vikram, D., Kaushik, S., Prashanth, V. \& Nallusamy, N., An improvement in the solar water heating systems by thermal storage using phase change materials. International Solar Energy Conference, 2006.

[4] Ding, Z., Wu, W., Chen, Y. \& Li, Y., Dynamic simulation and parametric study of solar water heating system with phase change materials in different climate zones. Solar Energy, 205, pp. 399-408, 2020.

[5] Dhinakaran, R., Muraliraja, R., Elansezhian, R., Baskar, S., Satish, S. \& Shaisundaram, V., Utilization of solar resource using phase change material assisted solar water heater and the influence of nano filler. Materials Today: Proceedings, 37, pp. 1281-1285, 2021.

[6] Saw, C., Al-Kayiem, H.H. \& Owolabi, A.L., Experimental investigation on the effect of PCM and nano-enhanced PCM of integrated solar collector performance. WIT Transactions on Ecology and the Environment, vol. 179, WIT Press: Southampton and Boston, pp. 899-909, 2013.

[7] Al-Kayiem, H.H., Energy sustainability through integrated solar thermal systems. WIT Transactions on Ecology and the Environment, vol. 179, WIT Press: Southampton and Boston, pp. 887-897, 2013.

[8] Carmona, M., Rincón, A. \& Gulfo, L., Energy and exergy model with parametric study of a hot water storage tank with PCM for domestic applications and experimental validation for multiple operational scenarios. Energy Conversion and Management, 222, pp. 113189, 2020.

[9] Kousksou, T., Bruel, P., Cherreau, G., Leoussoff, V. \& El Rhafiki, T., PCM storage for solar DHW: From an unfulfilled promise to a real benefit. Solar Energy, 85(9), pp. 2033-2040, 2011.

[10] Mahfuz, M., Anisur, M., Kibria, M., Saidur, R. \& Metselaar, I., Performance investigation of thermal energy storage system with Phase Change Material (PCM) for solar water heating application. International Communications in Heat and Mass Transfer, 57, pp. 132-139, 2014.

[11] Mannivannan, A. \& Ali, M.J., Simulation and experimental study of thermal performance of a building roof with a phase change material (PCM). Sadhana, 40(8), pp. 2381-2388, 2015.

[12] Chaabane, M., Mhiri, H. \& Bournot, P., Thermal performance of an integrated collector storage solar water heater (ICSSWH) with phase change materials (PCM). Energy Conversion and Management, 78, pp. 897-903, 2014.

[13] El Qarnia, H., Numerical analysis of a coupled solar collector latent heat storage unit using various phase change materials for heating the water. Energy Conversion and Management, 50(2), pp. 247-254, 2009. 
[14] Riahi, S., Saman, W., Bruno, F. \& Tay, N., Numerical study of melting process of a high-temperature phase change material including natural convection and turbulence. International Journal of Computational Methods and Experimental Measurements, 5(5), pp. 723-732, 2017.

[15] Costa, S.-C., Ismail, M., Kenisarin, M., Mahkamov, K., Mullen, D., Halimic, E. \& Lynn, K., Comparative study of two types of medium temperature phase change materials. WIT Transactions on Ecology and the Environment, vol. 237, WIT Press: Southampton and Boston, pp. 37-49, 2019.

[16] Nabavitabatabayi, M., Haghighat, F., Moreau, A. \& Sra, P., Numerical analysis of a thermally enhanced domestic hot water tank. Applied Energy, 129, pp. 253-260, 2014.

[17] Muñoz-Sánchez, B., Iparraguirre-Torres, I., Madina-Arrese, V., Izagirre-Etxeberria, U., Unzurrunzaga-Iturbe, A. \& García-Romero, A., Encapsulated high temperature PCM as active filler material in a thermocline-based thermal storage system. Energy Procedia, 69, pp. 937-946, 2015.

[18] Abokersh, M.H., Osman, M., El-Baz, O., El-Morsi, M. \& Sharaf, O., Review of the phase change material (PCM) usage for solar domestic water heating systems (SDWHS). International Journal of Energy Research, 42(2), pp. 329-357, 2018.

[19] Hosseini, M., Ranjbar, A., Sedighi, K. \& Rahimi, M., A combined experimental and computational study on the melting behavior of a medium temperature phase change storage material inside shell and tube heat exchanger. International Communications in Heat and Mass Transfer, 39(9), pp. 1416-1424, 2012.

[20] Wang, Z., Qiu, F., Yang, W. \& Zhao, X., Applications of solar water heating system with phase change material. Renewable and Sustainable Energy Reviews, 52, pp. 645652, 2015.

[21] Shareef, A., Al-Mousawi, F. \& Sachit, H., Experimental study of a PCM storage system integrated with a thermal solar collector. IOP Conference Series: Materials Science and Engineering, IOP Publishing, 2020.

[22] Khan, L.A., Khan, M.M., Dcu, D.B. \& Dcu, I.U.A., Numerical investigations on effect of nanoparticles on performance enhancement of paraffin RT64HC as phase change material.

[23] Amin, M., Putra, N., Kosasih, E.A., Prawiro, E., Luanto, R.A. \& Mahlia, T., Thermal properties of beeswax/graphene phase change material as energy storage for building applications. Applied Thermal Engineering, 112, pp. 273-280, 2017.

[24] Qin, Y., Wang, Z., Zhang, H., Dou, B., Zhang, G., Wu, W. \& Wu, C., The effect of phase change material balls on the thermal characteristics in hot water tanks: CFD research. Applied Thermal Engineering, 178, 115557, 2020.

[25] ANSYS Fluent, 18.2, Theory Guide, ANSYS Inc.: Canonsburg, PA, 2017. 